\title{
Congenital heart disease: current knowledge about causes and inheritance
}

Gillian M Blue MSc, GradDipGenCouns, Genetic Counsellor

Edwin P Kirk MB BS, PhD, FRACP Clinical Geneticist

Gary F Sholler MB BS, FRACP

Cardiologist

Richard P Harvey

Developmental Biologist

David S Winlaw

MB BS, MD, FRACS Paediatric Cardiac Surgeon

1 Heart Centre for Children The Children's Hospital at Westmead, Sydney, NSW.

2 Department of Medical Genetics, Sydney Children's Hospital, Sydney, NSW.

3 Victor Chang Cardiac Research Institute Sydney, NSW.

david.winlaw@ health.nsw.gov.au

MJA 2012; 197: 155-159 doi: 10.5694/mjal2.10811

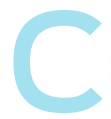

ongenital heart disease (CHD) affects $6-8$ babies in every 1000 live births. ${ }^{1}$ It is the most common cause of death from a congenital structural abnormality in newborns in the Western world, and is often associated with fetal loss. In Australia, over 2000 babies are born with CHD each year, with about half of these requiring surgery or catheter interventions. The other half have minor abnormalities (minor valve lesions or very small ventricular or atrial septal defects) that have no functional impact and rarely affect wellbeing or require intervention.

More patients with CHD require treatment each year than those with other significant conditions such as childhood cancer or cystic fibrosis (with 600 and 70 new cases, respectively, presenting each year in Australia). About a quarter of those requiring treatment will need surgery in the first year of life. Most infants and children requiring single interventions can expect to lead a nearnormal life. A small group of infants with complex lesions require multiple surgical procedures, intensive support and close monitoring during the first few years of life, although their quality of life may still be good. With the success of contemporary surgical procedures and improved survival, many patients with complex lesions are reaching adult life, and the population of adults with CHD now exceeds the number of children with structural heart abnormality. ${ }^{2}$

However, despite the improved treatment and prognosis of these patients, there is still a large gap in our knowledge of the aetiology of CHD. Determining a cause for CHD is important from a psychosocial perspective for the patient and family (whose main questions when faced with a new diagnosis of CHD are "why" and "how"), but also in regard to family planning for both the parents and the affected child as he or she approaches reproductive age. With the growing adult CHD population, information on recurrence risks and aetiology will become increasingly relevant. Understanding the aetiology of CHD will also benefit clinical management of the patient. It may help identify possible complications and risk factors for surgery or treatment, as patients with genetic syndromes or extracardiac anomalies are generally at higher risk of operative mortality and morbidity. ${ }^{3}$

Novel genetic techniques, such as whole exome and genome sequencing (Box 1), can accelerate gene discovery and assist in identifying causes of diseases of previously unknown aetiology, such as CHD. This review updates our current understanding of the causes and inheritance of CHD in light of the advances being made in genetic technologies.

\section{Summary \\ - About $80 \%$ of congenital heart disease (CHD) is multifactorial and arises through various combinations of genetic and environmental contributors. \\ - About $20 \%$ of cases can be attributed to chromosomal anomalies, Mendelian syndromes, non-syndromal single gene disorders or teratogens. Down syndrome and velocardiofacial syndrome are the most commonly seen syndromes in patients with CHD. \\ - To date, more than 30 genes have been linked to non- syndromal forms of $\mathrm{CHD}$. Their contribution to CHD remains unknown but is presumed to be relatively small. \\ - There is limited evidence for the contribution of specific environmental factors to CHD causation. However, folic acid supplementation in the pre- and peri-conception period, ensuring rubella vaccination has been completed before pregnancy, and maintaining good glycaemic control in mothers with diabetes may reduce the risk of CHD in infants. \\ - Recurrence risks vary between different types of non- syndromal $\mathrm{CHD}$ with multifactorial inheritance, and can be as high as $10 \%$ when two or more siblings are affected. Generally, the recurrence risk increases if a parent rather than a sibling is affected, particularly when the affected parent is the mother. \\ - Individualised recurrence risks can be generated for members of families affected by CHD after obtaining a detailed family history, including accurate cardiac diagnoses for all affected members. \\ - High-throughput genetic techniques can accelerate gene discovery and improve our ability to provide individualised genetic counselling.}

\section{Multifactorial congenital heart disease}

Currently, about $20 \%$ of CHD cases can be attributed to known causes such as genetic syndromes and teratogens, but very little is known about the aetiology of most cases (about $80 \%$ ). It is generally accepted that the group of CHD lesions with unknown aetiology follows a multifactorial inheritance model, which implicates both genetic and environmental factors in disease development. ${ }^{4}$ The prevailing model involves variations in many different genes, each of which contributes only a small amount to the individual's susceptibility to a particular condition. These interact with each other and with environmental factors to raise the likelihood that an individual will have CHD. Most sporadic cases of CHD (ie, isolated cases of CHD without a family history of the condition) would fall into this category. 


\section{Definitions of new genetic techniques}

Whole genome sequencing: Analysis of an individual's entire genetic code using a technique that allows multiple strands of DNA to be sequenced simultaneously, thereby greatly reducing the time required. Highly advanced bioinformatics analysis is essential to filter the large volume of information generated.

Whole exome sequencing: Analysis of the protein-coding region (the exome) that makes up 1\% of an individual's entire genome, using a technique that allows multiple strands of DNA to be sequenced simultaneously. The exome is thought to contain the majority of disease-causing mutations. Analysing only $1 \%$ of the genome greatly reduces the amount of information to be filtered and the cost of the process.

Genome-wide association studies: Studies in which associations between variations within the genome and diseases are made by rapid screening of a dense array of genetic markers. If variations occur at a statistically higher frequency in individuals with the disease compared with healthy controls, the variations are said to be associated with the disease.

\section{Chromosomal anomalies}

Chromosomal anomalies can cause CHD through several different mechanisms. Chromosomal material may be gained, as in Down syndrome, in which individuals have an additional chromosome 21, or it may be lost, as in velocardiofacial syndrome (VCFS), which is caused by loss of part of chromosome 22. Loss or gain of chromosomal material causes abnormality due to the effect on dosage-sensitive genes. For example, haploinsufficiency of TBX1 is responsible for many of the clinical features of VCFS, including the cardiac phenotype. ${ }^{5}$ Some phenotypic aspects could also be due to epigenetic effects and as yet unknown mechanisms. Chromosomal rearrangements, such as reciprocal translocations, can also cause problems by disrupting genes at the breakpoints on affected chromosomes, or by changing the relationship between a gene and its regulatory elements.

Chromosomal anomalies account for about $8 \%-10 \%$ of presenting cases of CHD. ${ }^{6}$ Down syndrome is the most common chromosomal anomaly seen in patients with CHD, followed closely by VCFS. About $40 \%-50 \%$ of patients with Down syndrome have a heart defect (Box $2),{ }^{10}$ and $80 \%$ of patients with VCFS have CHD, which usually includes lesions affecting the outflow tract and great vessels, such as tetralogy of Fallot (TOF). ${ }^{11}$ Although other syndromes, such as Edwards syndrome, may report higher percentages of patients with CHD presentation (Box 2), the prevalence of these syndromes is lower than Down syndrome and VCFS and therefore not seen as often.

Copy number variations $(\mathrm{CNV})$ - variations in the number of copies of a specific section of DNA present in an individual - are another type of chromosomal anomaly. Specific CNV have in the past been associated with diseases such as autism and schizophrenia and, more recently, with CHD. A recent study found that microduplications of the 1q21.1 region accounted for about $1 \%$ of the population attributable risk of TOF and that duplication of the GJA5 gene was associated with a 10-fold increase in risk of TOF. ${ }^{12}$

\section{Chromosomal anomalies associated with congenital heart disease (CHD) $)^{7-9}$}

\begin{tabular}{lccc} 
Syndrome & $\begin{array}{c}\text { Chromosomal } \\
\text { anomaly }\end{array}$ & Associated cardiac lesions & $\begin{array}{c}\text { Proportion of } \\
\text { patients with CHD }\end{array}$ \\
\hline Down & Trisomy 21 & AVSD, ASD, VSD, TOF & $40 \%-50 \%$ \\
\hline Edwards & Trisomy 18 & VSD, ASD, DORV, TOF, CoA, HLHS & $90 \%-100 \%$ \\
\hline Patau & Trisomy 13 & $\begin{array}{c}\text { ASD, VSD, DORV, HLHS, L-TGA, } \\
\text { AVSD, TAPVR, dextrocardia, PDA }\end{array}$ & $80 \%$ \\
\hline Turner & Monosomy X & CoA, AS, HLHS, PAPVR & $25 \%-35 \%$ \\
\hline Klinefelter & 47, XXY & ASD, PDA, MVP & $50 \%$ \\
\hline Cat eye & Tetrasomy 22p & TAPVR, PAPVR & $50 \%$ \\
\hline Pallister-Killian & Tetrasomy 12p & VSD, CoA, PDA, ASD, AS & $25 \%$ \\
\hline Velocardiofacial & (Del 22q11.2) & IAA(B), TA, TOF, aortic arch & $75 \%-85 \%$ \\
\hline Williams & (Del 7q11.23) & SVAS \pm PVS, PS, PPS & $50 \%-80 \%$ \\
\hline
\end{tabular}

$A S D=$ atrial septal defect. $A S=$ aortic stenosis. $A V S D=$ atrioventricular septal defect.

$\mathrm{COA}=$ coarctation of the aorta. DORV = double outlet right ventricle. HLHS = hypoplastic left heart syndrome. $I A A(B)=$ interrupted aortic arch (type $B$ ). L-TGA = congenitally corrected transposition of the great arteries. MVP = mitral valve prolapse. PAPVR = partial anomalous pulmonary venous return. $\mathrm{PDA}=$ patent ductus arteriosus. $\mathrm{PPS}=$ peripheral pulmonary stenosis. $\mathrm{PS}=$ pulmonary stenosis. $\mathrm{PVS}=$ pulmonary valve stenosis. SVAS = supravalvular aortic stenosis. TA = truncus arteriosus. TAPVR = total anomalous pulmonary venous return. TOF = tetralogy of Fallot. VSD = ventricular septal defect.

\section{Microdeletions and single gene disorders associated with congenital heart disease $(\mathrm{CHD})^{7-9}$}

\begin{tabular}{lccc} 
Syndrome & Gene (region) & Associated cardiac lesions & $\begin{array}{c}\text { Proportion of } \\
\text { patients with CHD }\end{array}$ \\
\hline Alagille & $\begin{array}{c}\text { JAG1, NOTCH1 } \\
\text { (del 2Opl2) }\end{array}$ & PPS, TOF, ASD, PS & $85 \%-95 \%$ \\
Noonan & PTPN17, SOS1, KRAS, RAFl & PVS, ASD, COA, HCM & $80 \%-90 \%$ \\
Holt-Oram & TBX5 & ASD, VSD, AVSD, TOF & $80 \%$ \\
Char & TFAP2B & PDA & $60 \%$ \\
$\begin{array}{l}\text { Ellis-van } \\
\text { Creveld }\end{array}$ & EVC, EVC2 & Primum ASD, common atrium, & $60 \%$ \\
Smith- & AVSD \\
Lemli-Opitz & DHCR7 & AVSD, primum ASD, VSD, & $45 \%$ \\
CHARGE & CHD7, SEMA3E & ASD, VSD, valve defects & $50 \%-80 \%$ \\
Kabuki & MLL2 in Some cases & CoA, ASD, VSD & $40 \%$ \\
Heterotaxy* & ZIC3 & Dextrocardia, L-TGA, AVSD, & $90 \%-100 \%$ \\
\hline
\end{tabular}

$A S D=$ atrial septal defect. $A V S D=$ atrioventricular septal defect. $C O A=$ coarctation of the aorta. $\mathrm{HCM}=$ hypertrophic cardiomyopathy. L-TGA = congenitally corrected transposition of the great arteries. PAPVR = partial anomalous pulmonary venous return. PDA = patent ductus arteriosus. PPS = peripheral pulmonary stenosis. PS = pulmonary stenosis. PVS = pulmonary valve stenosis TAPVR = total anomalous pulmonary venous return. TOF = tetralogy of Fallot. VSD = ventricular septal defect.

* Here refers to heterotaxy syndrome, which includes both cardiac and non-cardiac (eg, asplenia, polysplenia) manifestations. Heterotaxy is also an umbrella term for cardiac lesions, including left and right atrial isomerism.

\section{Mendelian syndromes}

CHD can be associated with extracardiac anomalies and in some cases can be diagnosed as being part of a syndrome. About 3\%-5\% of CHD can be attributed to Mendelian syndromes where a single mutation in the DNA results in pathological consequences, following a Mendelian inheritance pattern. ${ }^{13}$

Examples of Mendelian syndromes associated with CHD include Alagille syndrome, Holt-Oram syndrome and Noonan syndrome - these syndromes have a particularly high frequency of cardiac anomalies (Box 3). In most of the known Mendelian syndromes, the causal gene variation can be identified using current molecular genetic tests. As with chromosomal anomalies, 
there is variable expression within the cardiac phenotype of each syndrome, resulting in a range of possible cardiac lesions.

\section{Non-syndromal single gene disorders}

Research into CHD in the past 15 years has primarily focused on gene discovery in non-syndromal, familial forms of CHD. The proportion of cases falling into this group is still unknown, although it is presumed to be relatively small. Autosomal dominant inheritance is most common; however, the pathogenicity of the reported mutations and the role they play in disease phenotype and segregation is, in most cases, not very clear. Many of the genes reported to date encode transcription factors (proteins that regulate gene expression), but other types of proteins, particularly structural proteins such as cardiac actins and myosins, have also been implicated. The first two genes to be linked to non-syndromal CHD were NKX2-5 and GATA4; ${ }^{14}$ more than 30 genes have since been associated. A selection of the more well known genes is shown in Box $4 .{ }^{1}$ Gene discovery in the field has relied on traditional techniques, such as linkage analysis and candidate gene approaches. While these techniques have been successful in other research fields, they rely on large families with multiple affected members and prior knowledge of biological pathways - both of which are a rarity in $\mathrm{CHD}$.

\section{Environmental factors and teratogens}

Environmental factors influencing CHD can be broadly defined as any "non-genetic" factor with an associated risk of CHD development. These usually occur within a maternal preconceptional or fetal-placental-maternal context. The contribution of specific environmental exposures to the causation of CHD in general is unknown, as most associations have been derived from small observational studies, which have not been replicated and may have been complicated by recall bias and confounding effects.

The best documented maternal risk factor is maternal diabetes, with a reported fivefold increased risk of CHD from pregestational diabetes. ${ }^{16}$ As the time of greatest risk for development of $\mathrm{CHD}$ is before the 7 th week of gestation, the types of CHD most commonly associated with maternal diabetes are those due to defects of primary cardiogenesis, such as heterotaxy, atrioventricular septal defect and outflow tract anomalies. ${ }^{17}$ The exact mechanisms by which diabetes induces CHD are unknown. One theory suggests that abnormal glucose levels may disrupt expression of regulatory genes in the embryo, thereby resulting in cell death. Another hypothesis is that oxidative stress and the production of free radicals resulting from changes in metabolism may be to blame. Strict glycaemic control before conception and during pregnancy has been reported to reduce the risk of infants developing CHD. ${ }^{18}$

Other environmental factors have been associated with an increased risk of CHD (Box 5), although findings are generally inconclusive. For example, studies providing supportive evidence of a protective effect of

\begin{tabular}{|c|c|c|}
\hline Gene & Function & Associated cardiac lesions \\
\hline$N K \times 2-5$ & Transcription factor & $\begin{array}{c}\text { ASD-AV block, TOF, HLHS, TGA, DORV, } \\
\text { Ebstein anomaly, VSD }\end{array}$ \\
\hline$N K \times 2-6$ & Transcription factor & TA \\
\hline GATA4 & Transcription factor & $\mathrm{ASD} \pm \mathrm{PS}, \mathrm{TOF}, \mathrm{VSD}, \mathrm{DORV}$ \\
\hline GATA6 & Transcription factor & TA, TOF, AVSD \\
\hline TBXI & Transcription factor & IAA, aortic arch anomalies, VSD \\
\hline TBX5 & Transcription factor & ASD, VSD, AVSD, conduction abnormalities \\
\hline$T B \times 20$ & Transcription factor & ASD, VSD, valve defects, LVOTO \\
\hline CITED2 & Transcription factor & ASD, VSD, TOF, TGA \\
\hline ZIC3 & Transcription factor & Heterotaxy, ASD, AVSD, TGA, VSD, TAPVR, PS \\
\hline ZFPM2 & Transcription factor & TOF \\
\hline FOXHI & Transcription factor & TOF, VSD \\
\hline HANDI & Transcription factor & HLHS (somatic mutation) \\
\hline TFAP2B & Transcription factor & PDA \\
\hline $\mathrm{NOTCHT}$ & Membrane ligand-receptor & AS, BAV \\
\hline NODAL & Membrane ligand-receptor & Heterotaxy, TGA \\
\hline$J A G 1$ & Membrane ligand-receptor & PS, TOF \\
\hline CFCl & Membrane ligand-receptor & Heterotaxy, TGA, DORV, TOF \\
\hline MYH6 & Sarcomeric protein & ASD \\
\hline MYH7 & Sarcomeric protein & ASD, Ebstein anomaly \\
\hline MYH11 & Sarcomeric protein & PDA \\
\hline ACTC1 & Sarcomeric protein & ASD, VSD \\
\hline GJAl & Gap junction protein & HLHS (somatic mutation) \\
\hline GJA5 & Gap junction protein & TOF \\
\hline CRELDI & Matricellular protein & AVSD, dextrocardia \\
\hline$E L N$ & Structural protein & SVAS \\
\hline VEGFA & Mitogen & TOF \\
\hline
\end{tabular}

$\mathrm{ASD}=$ atrial septal defect. $\mathrm{AS}=$ aortic stenosis. $\mathrm{AV}=$ atrioventricular. $\mathrm{AVSD}=$ atrioventricular septal defect. BAV = bicuspid aortic valve. DORV = double outlet right ventricle. HLHS = hypoplastic left heart syndrome. IAA = interrupted aortic arch. LVOTO = left ventricular outflow tract obstruction. PDA = patent ductus arteriosus. PS = pulmonary stenosis. SVAS = supravalvular aortic stenosis. TA = truncus arteriosus. TAPVR = total anomalous pulmonary venous return. TGA = transposition of the great arteries. TOF = tetralogy of Fallot. VSD = ventricular septal defect.

periconceptional folate and folic acid-containing multivitamin supplementation were too small to provide definite answers. ${ }^{19}$ Additional population-based studies and randomised clinical trials are needed to confirm their findings. Maternal febrile illness is also questionable as a risk factor, as most studies were unable to distinguish between possible confounding effects of medications taken to reduce illness. Potential confounding effects have also been seen in studies investigating maternal antidepressant use, specifically selective serotonin reuptake inhibitors (SSRIs), although consistent evidence supporting an increase in CHD after use of some SSRIs warrants further study. ${ }^{20}$

Despite the inconclusive evidence reported, it seems reasonable to suggest a few basic recommendations aimed at minimising possible CHD risk factors for women who are or intend to become pregnant:

- Daily folic acid supplementation in the pre- and periconception period

- Ensuring rubella vaccination is complete before pregnancy - Optimal management of other known risk factors, such as diabetes and phenylketonuria, before and during pregnancy 
- Avoiding medication use before and during pregnancy, if possible. Where the use of medication is unavoidable, it should be discussed with medical professionals.

\section{Contribution of "flow"}

Normal circulation in the developing fetus is an important promoter of growth and chamber development. ${ }^{21}$ In complex forms of CHD, where multiple anomalies exist, it is conventionally thought that individual structural defects may explain "downstream" changes. For example, severe mitral stenosis or atresia may be associated with underdevelopment of the left ventricle, aortic valve and ascending aorta. It is likely that the situation is more complex than this, with translational studies suggesting that individual genetic mutations may cause a range of abnormalities affecting both cardiac valves and chamber myocardium. ${ }^{22}$ Defining the genetic and molecular underpinning of these abnormalities is important in understanding the growth potential of cardiac structures in affected individuals.

\section{Alternative hypothesis}

Controversy has surrounded the suggestion that multiple somatic mutations - mutations present in affected tissue but not in the germline - may cause sporadic CHD. However, subsequent studies have not replicated this finding and it appears unlikely that this is an important causal mechanism for CHD. ${ }^{23}$

\section{Recurrence risks in congenital heart disease}

In a minority of cases, it is possible to provide a precise recurrence risk for $\mathrm{CHD}$, based on known Mendelian inheritance in a family or on risk figures related to a chromosomal anomaly. In the absence of such information, empirical risk estimates must be used. For most lesions, the reported recurrence risk in siblings of an affected individual, when neither parent is affected, is in the range of $1 \%-6 \%$ (Box 6 ). ${ }^{24,25}$ If more than one sibling is affected, the recurrence risk can increase to $10 \%{ }^{26}$ The recurrence risk in offspring of affected parents is generally significantly higher than that in siblings of affected individuals with unaffected parents. Further, if the mother is the affected parent, the risk of disease transmission is higher. ${ }^{25}$ The reason for these differences is unknown, and it is difficult to reconcile them with known genetic mechanisms.

Recurrence risks also vary considerably among different types of CHD. Obstructive left heart lesions, including hypoplastic left heart syndrome, aortic valve stenosis and coarctation of the aorta, generally have noticeably higher recurrence risks in siblings of unaffected parents and/or offspring of affected parents compared with other types of CHD. ${ }^{27}$ It is reported that up to $20 \%$ of the asymptomatic first-degree relatives of patients with obstructive left heart lesions may have undiagnosed CHD, in particular bicuspid aortic valve (BAV). ${ }^{28}$ Although not classically considered a childhood heart defect, BAV may require treatment later in life, including valve replacement and aortic surgery.
5 Environmental risk factors associated with congenital heart disease (CHD) ${ }^{8,9,17}$

\begin{tabular}{|c|c|c|}
\hline Teratogenic influence & Associated cardiac lesions & $\begin{array}{l}\text { Proportion at } \\
\text { risk of } \mathrm{CHD}\end{array}$ \\
\hline Maternal diabetes & $\begin{array}{c}\text { VSD, ASD, L-TGA, AVSD, TAPVR, CoA, } \\
\text { TOF, TGA }\end{array}$ & $5 \%$ \\
\hline Maternal rubella & PDA, VSD, ASD, PS, TOF & $30 \%-60 \%$ \\
\hline Maternal phenylketonuria & TOF, VSD, PDA, left-sided lesions & $15 \%-50 \%$ \\
\hline Systemic lupus erythematosus & Complete heart block & Uncertain \\
\hline Febrile illness & $\begin{array}{l}\text { PS, right- and left-sided obstructive } \\
\text { defects, tricuspid atresia, VSD }\end{array}$ & Uncertain \\
\hline Thalidomide & TOF, ASD, VSD, TA & Up to $30 \%$ \\
\hline Retinoic acid & TA, TOF, IAA, DORV & $25 \%$ \\
\hline Anticonvulsants & Any defect & Uncertain \\
\hline Lithium & Ebstein anomaly, tricuspid atresia & $\begin{array}{l}\text { Lower than } \\
\text { initially } \\
\text { reported }\end{array}$ \\
\hline Selective serotonin reuptake inhibitors & VSD, ASD, TOF & Uncertain \\
\hline Alcohol & VSD, ASD, TOF & Uncertain \\
\hline Marijuana & VSD, Ebstein anomaly & Uncertain \\
\hline
\end{tabular}

$A S D=$ atrial septal defect. AVSD = atrioventricular septal defect. CoA = coarctation of the aorta. $\mathrm{DORV}=$ double outlet right ventricle. IAA = interrupted aortic arch. L-TGA = congenitally corrected transposition of the great arteries. PDA = patent ductus arteriosus. PS = pulmonary stenosis. TA = truncus arteriosus. TAPVR = total anomalous pulmonary venous return. TGA = transposition of the great arteries. TOF $=$ tetralogy of Fallot. VSD $=$ ventricular septal defect.

\section{Recurrence risk (RR) of different types of congenital heart disease (CHD)}

\begin{tabular}{|c|c|c|c|c|}
\hline \multirow{2}{*}{$\begin{array}{l}\text { Cardiac } \\
\text { lesion }\end{array}$} & \multicolumn{2}{|c|}{$\begin{array}{l}\text { RR in siblings with } \\
\text { unaffected parents }\end{array}$} & \multicolumn{2}{|c|}{$\begin{array}{l}\text { RR in children of } \\
\text { affected parents }\end{array}$} \\
\hline & 1 child affected & $\geqslant 2$ children affected & Mother affected & Father affected \\
\hline VSD & $3 \%$ & $10 \%$ & $9 \%-10 \%$ & $2 \%-3 \%$ \\
\hline ASD & $2 \%-3 \%$ & $8 \%$ & $6 \%$ & $1 \%-2 \%$ \\
\hline TOF & $2 \%-3 \%$ & $8 \%$ & $2 \%-5 \%$ & $1 \%-2 \%$ \\
\hline CoA & $2 \%$ & $6 \%$ & $4 \%$ & $2 \%-3 \%$ \\
\hline AS & $2 \%$ & $6 \%$ & $12 \%-20 \%$ & $5 \%$ \\
\hline PS & $2 \%$ & $6 \%$ & $6 \%-7 \%$ & $2 \%$ \\
\hline HLHS & $3 \%$ & $10 \%$ & $\mathrm{nr}$ & $\mathrm{nr}$ \\
\hline AVSD & $3 \%-4 \%$ & $\mathrm{nr}$ & 10\%-14\% & $1 \%$ \\
\hline PA & $1 \%$ & $3 \%$ & $\mathrm{nr}$ & $\mathrm{nr}$ \\
\hline TA & $1 \%$ & $3 \%$ & $\mathrm{nr}$ & $\mathrm{nr}$ \\
\hline TGA & $1 \%-2 \%$ & $5 \%$ & $\mathrm{nr}$ & $\mathrm{nr}$ \\
\hline L-TGA & $5 \%-6 \%$ & $\mathrm{nr}$ & $\mathrm{nr}$ & $\mathrm{nr}$ \\
\hline $\begin{array}{l}\text { Ebstein } \\
\text { anomaly }\end{array}$ & $1 \%$ & $3 \%$ & $6 \%$ & $\mathrm{nr}$ \\
\hline Heterotaxy & $5 \%-6 \%$ & $\mathrm{nr}$ & $\mathrm{nr}$ & $\mathrm{nr}$ \\
\hline Overall & $1 \%-6 \%$ & $3 \%-10 \%$ & $2 \%-20 \%$ & $1 \%-5 \%$ \\
\hline
\end{tabular}

$\mathrm{ASD}=$ atrial septal defect. $\mathrm{AS}=$ aortic stenosis. $\mathrm{AVSD}=$ atrioventricular septal defect. $\mathrm{CoA}=$ coarctation of the aorta. HLHS = hypoplastic left heart syndrome. L-TGA = congenitally corrected transposition of the great arteries. $\mathrm{nr}=$ not reported. $\mathrm{PA}=$ pulmonary atresia. $\mathrm{PS}=$ pulmonary stenosis. $\mathrm{TA}=$ truncus arteriosus. TGA = transposition of the great arteries. TOF = tetralogy of Fallot. VSD = ventricular septal defect.

Concordance of recurrent CHD (ie, the same subtype of $\mathrm{CHD}$ ) within members of the same family can vary substantially between different types of CHD. The overall exact concordance of recurrent CHD is reportedly $37 \%$, with a group concordance (ie, within the same spectrum of $\mathrm{CHD}$ ) of $47 \% .^{29}$

\section{Future directions}

Recent advances in technology provide us with the potential to better understand conditions with a genetic 
component that have not previously been well understood. Revolutionary techniques such as whole genome and exome sequencing still harbour many challenges, including the analysis of large amounts of data and the difficulty in distinguishing benign variants from diseasecausing mutations. However, the prospect of novel gene discovery and possible identification of disease aetiology greatly outweighs these challenges. For conditions with complex, multifactorial inheritance, such as CHD, these novel techniques hold much promise. Unlike traditional research techniques, they provide an unbiased approach, in which both rare and common variants can be identified, making them more suitable to the study of complex diseases.

Accelerated gene discovery in CHD will translate into more individualised genetic counselling for patients and their families, and the role of genetics in the clinical care of patients with CHD should continue to evolve. For now, ensuring an accurate family history is obtained, including detailed cardiac diagnoses for all affected family members, could provide valuable clues about possible causation and inheritance. This is particularly relevant to families with multiple affected individuals, and a referral to a genetics service should be considered.

Acknowledgements: We thank the New South Wales Cardiovascular Research Network (Heart Foundation of Australia and NSW Office for Science and Medical Research) for funding and support.

Competing interests: No relevant disclosures.

Provenance: Not commissioned; externally peer reviewed.

1 Wessels MW, Willems PJ. Genetic factors in non-syndromic congenital heart malformations. Clin Genet 2010; 78: 103-123.

2 Khairy P, Ionescu-Ittu R, Mackie AS, et al. Changing mortality in congenital heart disease. J Am Coll Cardiol 2010; 56: 1149-1157.

3 Formigari R, Michielon G, Digilio MC, et al. Genetic syndromes and congenital heart defects: how is surgical management affected? Eur J Cardiothorac Surg 2009; 35:606-614

4 Nora JJ. Multifactorial inheritance hypothesis for the etiology of congenital heart diseases: the genetic-environmental interaction. Circulation 1968; 38 : 604-617.

5 Merscher S, Funke B, Epstein JA, et al. TBX] is responsible for cardiovascular defects in velo-cardio-facial/DiGeorge syndrome. Cell 2001; 104: 619-629.

6 Roos-Hesselink JW, Kerstjens-Frederikse WS, Meijboom FJ, Pieper PG. Inheritance of congenital heart disease. Neth Heart J 2005; 13: 88-91.

7 Pierpont ME, Basson CT, Benson DW Jr, et al. Genetic basis for congenital heart defects: current knowledge: a scientific statement from the American Heart Association Congenital Cardiac Defects Committee, Council on Cardiovascular Disease in the Young: endorsed by the American Academy of Pediatrics. Circulation 2007: 115: 3015-3038.

8 Burn J, Goodship J. Congenital heart disease. In: Rimoin DL, Connor JM, Pyeritz RE, Korf BR, editors. Emery and Rimoin's principles and practice of medical genetics. 4th ed. London: Churchill Livingstone, 2002: 1239-1272.

9 Lin AE, Ardinger HH. Genetic epidemiology of cardiovascular malformations. Prog Pediatr Cardiol 2005; 20: 113-126.
10 American Academy of Pediatrics Committee on Genetics. Health supervision for children with Down syndrome. Pediatrics 2001; 107: 442-449.

11 Botto LD, May K, Fernhoff PM, et al. A population-based study of the 22q11.2 deletion: phenotype, incidence, and contribution to major birth defects in the population. Pediatrics 2003; 112: 101-107.

12 Soemedi R, Topf A, Wilson IJ, et al. Phenotype-specific effect of chromosome lq21.1 rearrangements and GJA5 duplications in 2436 congenital heart disease patients and 6760 controls. Hum Mol Genet 2012; 21: 1513-1520.

13 van der Bom T, Zomer AC, Zwinderman AH, et al. The changing epidemiology of congenital heart disease. Nat Rev Cardiol 2011; 8: 50-60.

14 Butler TL, Esposito G, Blue GM, et al. GATA4 mutations in 357 unrelated patients with congenital heart malformation. Genet Test Mol Biomarkers 2010; 14:797-802.

15 Jongbloed JD, Pósafalvi A, Kerstiens-Frederikse WS, et al. New clinical molecular diagnostic methods for congenital and inherited heart disease. Expert Opin Med Diagn 2011; 5: 9-24.

16 Wren C, Birrell G, Hawthorne G. Cardiovascular malformations in infants of diabetic mothers. Heart 2003; 89: 1217-1220.

17 Jenkins KJ, Correa A, Feinstein JA, et al. Noninherited risk factors and congenital cardiovascular defects: current knowledge: a scientific statement from the American Heart Association Council on Cardiovascular Disease in the Young: endorsed by the American Academy of Pediatrics. Circulation 2007; 115 : 2995-3014.

18 Cousins L. Etiology and prevention of congenital anomalies among infants of overt diabetic women. Clin Obstet Gynecol 1991; 34: 481-493.

19 Botto LD, Olney RS, Erickson JD. Vitamin supplements and the risk for congenital anomalies other than neural tube defects. Am JMed Genet C Semin Med Genet 2004; 125C: 12-21.

20 Wurst KE, Poole C, Ephross SA, Olshan AF. First trimester paroxetine use and the prevalence of congenital, specifically cardiac, defects: a meta-analysis of epidemiological studies. Birth Defects Res A Clin Mol Teratol 2010; 88: 159-170.

21 Hove JR, Koster RW, Forouhar AS, et al. Intracardiac fluid forces are an essential epigenetic factor for embryonic cardiogenesis. Nature 2003; 421: $172-177$.

22 Kirk EP, Sunde M, Costa MW, et al. Mutations in cardiac T-box factor gene TBX2O are associated with diverse cardiac pathologies, including defects of septation and valvulogenesis and cardiomyopathy. Am J Hum Genet 2007; 81: 280-291.

23 Esposito G, Butler TL, Blue GM, et al. Somatic mutations in NKX2-5, GATA4, and $H A N D l$ are not a common cause of tetralogy of Fallot or hypoplastic left heart. Am J Med Genet A 2011; 155A: 2416-2421.

24 Calcagni G, Digilio M, Sarkozy A, et al. Familial recurrence of congenital heart disease: an overview and review of the literature. Eur J Pediatr 2007; 166: $111-116$.

25 Burn J, Brennan P, Little J, et al. Recurrence risks in offspring of adults with major heart defects: results from first cohort of British collaborative study. Lancet 1998; 351: 311-316.

26 Nora JJ, Nora AH, Optiz JM, Reynolds JF. Update on counseling the family with a first-degree relative with a congenital heart defect. Am J Med Genet 1988; 29: $137-142$.

27 Lewin MB, McBride KL, Pignatelli R, et al. Echocardiographic evaluation of asymptomatic parental and sibling cardiovascular anomalies associated with congenital left ventricular outflow tract lesions. Pediatrics 2004; 114: 691-696.

28 Kerstjens-Frederikse WS, Du Marchie Sarvaas GJ, Ruiter JS, et al. Left ventricular outflow tract obstruction: should cardiac screening be offered to first-degree relatives? Heart 2011; 97: 1228-1232.

29 Gill HK, Splitt M, Sharland GK, Simpson JM. Patterns of recurrence of congenital heart disease: an analysis of 6,640 consecutive pregnancies evaluated by detailed fetal echocardiography. J Am Coll Cardiol 2003; 42: 923-929. 